\title{
Leitura literária e vivência criativa no espaço carcerário
}

\section{Literary reading and creative living in the prison setting}

\author{
Sheila Oliveira Lima * \\ Henrique Furtado de Melo "
}

Resumo: A literatura é vista por muitos teóricos como elemento essencial na formação do ser humano. Sua leitura pode suscitar deslocamentos subjetivos devido à capacidade de provocar o ato criativo. Neste artigo, apresentamos os resultados de pesquisa realizada em ambiente carcerário, na qual foi proposta a leitura de textos literários a um grupo de detentos. Os resultados, aferidos por meio de registros escritos em gênero livre, revelam a necessidade de investimentos culturais, por meio da leitura literária, como forma de ressignificar as trajetórias dos apenados e promover uma efetiva reinserção social de grupos marginalizados.

Palavras-chave: leitura, literatura, penitenciária.

Abstract: Literature is seen by many theorists as a key element in the formation of human beings. His reading may raise subjective displacements due to the ability to cause the criative act. This article presents the results of research conducted in the prision system, in which it was proposed the reading of literary texts to a group of detainees. The results measured by means of written records on gender free, reveal the need for cultural investments, through literary reading, as a way to reframe the trajectories of inmates and promote effective social reintegration of marginalized groups.

Keywords: reading, literature, penitentiary.

\footnotetext{
Doutora em Educação pela USP. Pesquisadora vinculada ao PROFLETRAS (Programa de Mestrado Profissional em Letras) da Universidade Estadual de Londrina e ao Programa de Pós-Graduação em Estudos da Linguagem da UEL.

घestrando do Programa de Pós-Graduação de Literatura da UEL.
} 


\section{ntrodução}

Diante da compreensão de Antonio Candido (1995) de que a literatura deve ser considerada bem incompressível, direito humano, não devendo, portanto, ser negada a qualquer um, em qualquer espaço, firmamos nossas pesquisas, buscando implementar e pensar novas políticas de leitura do texto literário, desde os anos inicias do Ensino Fundamental, até outros espaços para além dos muros escolares, em especial aqueles convencionalmente distanciados da literatura, como o cárcere. Neste trabalho procuramos refletir acerca do lugar da literatura no sistema penal, através do vínculo que pudemos estabelecer entre os projetos "Leitura literária no ensino fundamental - ciclo 1: concepções e práticas", da Universidade Estadual de Londrina, e "Remição pela Leitura", da Secretaria de Justiça, Cidadania e Direitos Humanos do Paraná (SEJU-PR).

Amparados em pesquisas de autores ligados a teorias de base psicanalítica, como Vincent Jouve (2002) e Michèle Petit (2009), buscamos destacar a importância da movimentação do impulso criativo, na construção do que D.W. Winnicott $(1975 ;$ 2012) denomina espaço transicional, por meio do qual é possível (re) tomar uma vivência criativa.

Através da análise de textos produzidos por apenados durante uma atividade de leitura que promovemos, será possível verificar como a leitura literária pôde funcionar como propulsora no processo de construção de espaços transicionais, proporcionando aos leitores a oportunidade de dar alguns passos no caminho de uma recolocação de si na posição de narradores da própria história de vida; reafirmando a literatura na qualidade de bem imprescindível à vida humana.

\section{Literatura e impulso criativo}

Até o século XVIII, no mundo europeu e, consequentemente em suas colônias e pós-colônias, o castigo físico aos que praticavam algum tipo de crime variava conforme os agravantes da situação. A tortura nas prisões - e, por vezes, em público, como ato que precedia a execução à morte em praça pública - representava uma das vias de salvação da alma do detento por meio da dor e da mutilação. As execuções àquela época, mais do que se ocupar da segurança e da correção de uma sociedade, buscavam um domínio do povo por meio do medo impingido 
pelas penas severas, tornadas atrativos espetáculos nos cadafalsos centrais das cidades.

Com o passar dos séculos, a pena desloca-se, paulatinamente, do corpo para a alma e da exposição do castigo para sua realização interna aos presídios. Vale lembrar que, até meados do século XX, a guilhotina ainda era utilizada na França, mas já sem exposição pública. No Brasil do século XXI, a tortura nos presídios e delegacias - já não mais com a finalidade de salvação da alma - é uma prática, em certa medida, frequente, mas não mais aceita e, por essa razão, proibida e objeto de denúncias e punições.

Assim, hoje, o que resta de uma história de condenações e ações penais, no Brasil, como em boa parte dos países do Ocidente, limita-se à restrição da liberdade, distante resquício da busca pela salvação da alma a partir da retirada de um dos maiores bens do homem. A sensação de distância do mundo e dos valores da sociedade torna-se um grave flagelo. Em vez das mutilações do corpo, hoje se têm as da alma: a diluição dos vínculos familiares, a restrição dos lazeres, a vigilância irrestrita, a perda da privacidade, entre outros.

No Paraná, decorrente do seu contexto penal, foi criado, no ano de 2013, o projeto Remição pela Leitura, como um meio de oportunizar o acesso ao benefício da remição por estudo, prevista pela Lei 12.433 de 2011. A proposta prevê que, mensalmente, os apenados matriculados leiam um livro, dentre os previamente selecionados pela coordenação do projeto, produzindo uma resenha ou relatório de leitura (de acordo com o nível de escolaridade) como documento de comprovação para remição de 4 dias da pena por mês. A Comissão de Remição pela Leitura do estabelecimento penal somente computa a remição caso a resenha ou relatório sejam avaliados em, no mínimo $60 \%$ de aproveitamento. A leitura, nesse universo - de valor semelhante ao trabalho e à escola -, é inserida como adensamento da pena. Subjaz, nessa atividade, o entendimento de que a leitura do texto literário representa esforço maior que a prisão comum. Nesse contexto, a atividade leitora, no rastro da história das penas, pode ser considerada uma punição, senão mais grave que a perda da liberdade, certamente semelhante a ela. Dessa forma, corre o risco de representar, dentro prisional do espaço prisional, não um investimento na formação do sujeito, mas tão somente um elemento a mais que, de acordo com Foucault (1986), compõe o quadro da restrição da alma na condução para o perdão. 
Entretanto, a leitura autêntica do texto literário, isto é, fora do âmbito e a partir da demanda pessoal do leitor, aponta outro sentido. Segundo Candido (1995), a literatura está diretamente relacionada à formação do homem, sendo um bem do qual não é possível prescindir. Para o teórico, que considera literatura toda manifestação do universo fabulado, seja oral ou escrita, popular ou erudita, não há povo ou sujeito que possa viver, formar-se, sem o contato com ela.

A leitura literária, então, para além de uma atividade de lazer ou entretenimento, pode ser compreendida como um elemento fundamental na formação do homem, no adensamento da sua condição humana, justamente pelo seu caráter "pedagógico", ou melhor, pelo seu potencial de vivência das emoções mais fundamentais para a formação do sujeito.

Nesse aspecto, Candido afirma que:

A literatura pode formar; mas não segundo a pedagogia oficial, que costuma vê-la ideologicamente como um veículo da tríade famosa, - o Verdadeiro, o Bom, o Belo [...] Longe de ser apêndice da instrução moral e cívica (esta apoteose matreira do óbvio, novamente em grande voga), ela age com o impacto indiscriminado da própria vida e educa como ela, - com altos e baixos, luzes e sombras (CANDIDO, 1999, p. 84).

Posto que a literatura atua na formação do humano, através de vivências ficcionais, podemos dar um passo adiante: além de formadora, ela pode também agir como transformadora da condição humana. Num contexto como o da penitenciária, não é raro encontrar indivíduos cujas vidas foram forjadas em experiências tensas e consideradas pouco edificantes, segundo o ponto de vista de uma sociedade conservadora. O convívio com crimes de toda ordem desde a mais tenra infância parece, em muitos casos, traçar contornos indeléveis à ação do sujeito, impossibilitando uma ideal remição, mais próxima da "correção" das rotas do que do cumprimento burocrático da pena.

A literatura, entretanto, em seu potencial de formação do sujeito, quando não opera num tipo de construção, para a qual as experiências mais radicais são vivenciadas pelo toque poético, parece poder contribuir para a ressignificação do vivido, por mais traumático que este possa haver se constituído.

Incitar o leitor a (res)significar a memória, parece-nos ser ponto crucial no processo de reinterpretação da própria narrativa de vida do leitor, processo este 
que compõe nosso interesse central no que diz respeito ao contato dos apenados com a literatura. A prática da leitura literária no contexto prisional, nesse sentido, pode gerar situações de intenso resgate da subjetividade, mesmo quando essa dimensão não esteja compreendida entre os objetivos iniciais de sua inserção em tal ambiente.

O contexto carcerário, frequentemente entendido como punição e não como meio de reconstituição de trajetórias de vida por vezes repletas de obstáculos a oportunidades construtivas, coloca homens e mulheres em situações de desumanização, de apagamento identitário: olhares proibidos de se desviarem das paredes, cabeças baixas e o medo constante de se expressar; ser torna-se uma subversão.

Nesse ambiente de absoluta delimitação e mesmo de cerceamento do ser, da subjetividade, a leitura do texto literário surge como possibilidade de expressão a partir do enlace entre o leitor e o texto. $\mathrm{O}$ ato de ler, em geral considerado apenas em sua instância cognitiva, para Jouve, entre outros pesquisadores ligados a teorias de base psicanalítica, deve ser compreendido como uma atividade criativa.

Jouve (2002) ressalta o fato de a leitura evocar elementos da subjetividade, na medida em que sempre está enlaçada a uma primeira experiência infantil com a dimensão do narrar. Nesse sentido, o ato de ler parece se constituir de uma relação com o texto em que o leitor aceita o jogo proposto, mas, de todo modo, é quem conduz as próprias "jogadas". É no interior de sua memória, de sua experiência individual, que busca as referências para compor os cenários narrados ou para materializar o instante eternizado pelo poema. Trata-se, portanto, de uma atividade de intensa produção criativa.

Winnicott, cuja perspectiva teórica também se fundamenta na psicanálise freudiana, após apontar correspondências entre o brincar criativo da criança e o ato criativo ao longo da vida, afirma que "É no brincar, e somente no brincar, que o indivíduo, criança ou adulto, pode ser criativo e utilizar sua personalidade integral: e é somente sendo criativo que o indivíduo descobre o eu (self)." (WINNICOTT, 1975, p.80, grifo nosso). A descoberta do self, para Winnicott, portanto, está intimamente ligada à movimentação do impulso criativo, algo que, para ele, está presente sempre que qualquer pessoa se direciona saudavelmente a alguma coisa ou se propõe a fazer ou construir algo. Nesse sentido, 
é possível estabelecer, e estabelecer utilmente, um vínculo entre o viver criativo e o viver propriamente dito. É possível estudar as causas da perda desse viver criativo: por que pode desaparecer o sentimento que o indivíduo tem de que a vida é real ou significativa (WINNICOTT, 1975, p.100-101).

A descoberta do self é importante no contexto que discutimos, na medida em que a leitura literária, como processo criativo, pode proporcionar ao apenado um movimento de (re)tomada da posição de sujeito (e não objeto) da própria narrativa de vida, reafirmando sua subjetividade e centralidade no percurso de humanização.

Petit, após vasta pesquisa sobre a interferência da leitura como forma de amenizar o sofrimento em cenários de crise social, observa a possibilidade de os sujeitos se apoderarem da literatura como meio de preservação do resquício de humanidade que ainda Ihes resta em tais situações. Ao se referir aos sujeitos aos quais ofereceu a literatura como alternativa ao sofrimento, a pesquisadora conclui:

Eles não economizam meios, não economizam textos - ou, às vezes, imagens capazes de abrir o horizonte para resistir ao confinamento, aos constrangimentos e às eventuais tentativas dos poderes - políticos, simbólicos ou domésticos - de entravar, estreitar e controlar seus movimentos. Eles se esforçam para salvaguardar um conhecimento próprio e do mundo, para preservar frente e contra tudo um espaço de pensamento, uma dignidade e uma parte de liberdade, de sonho, de inesperado (PETIT, 2009, p. 289).

Nesse sentido podemos considerar o contexto prisional um espaço repleto de fatores ambientais que sufocam os processos criativos dos sujeitos em situação de cárcere, uma vez que há um persistente apagamento das vozes desses sujeitos no objetivo de contê-los. Por vezes, vimos apenados realizarem trabalhos artesanais de extrema delicadeza, embora clandestinos dentro do sistema, pois, ainda que não constituíssem ameaça alguma do ponto de vista da segurança, muitos desses itens artesanais foram e são entendidos como subversão, uma vez que são realizados sem que a equipe de segurança saiba, sem que os permita.

Um exemplo muito significativo desses artesanatos foi um grande volume de cartões decorativos produzidos com lápis coloridos conseguidos na escola e pe- 
quenas esculturas de flores feitas de restos de sabonete coladas sobre folhas de papel. Quando observamos que esses itens artesanais são frequentemente tomados como espécie de desobediência ao sistema, como subversão, podemos perceber que, por meio dessas alternativas artísticas rudimentares, o sujeito encarcerado busca marcar-se no mundo, ser através da movimentação do impulso criativo; e ser, não parece algo permitido a um sujeito em cumprimento de pena reclusiva.

Ainda em torno desse aspecto, Winnicott reforça que:

Se tomamos conhecimento de indivíduos dominados no lar, prisioneiros, ou mortos em campos de concentração, ou vítimas da perseguição de um regime político cruel, supomos, antes de mais nada, que somente algumas dessas vítimas permaneceram criativas. Estas, naturalmente, são aquelas que sofrem. Parece, a princípio, que todos os outros que existem (não vivem) nessas comunidades patológicas abandonaram a esperança, deixaram de sofrer e perderam a característica que os torna humanos, de modo a não mais perceberem o mundo de maneira criativa. Estas circunstâncias representam o lado negativo da civilização. Referimo-nos à destruição da criatividade em indivíduos pela ação de fatores ambientais, numa data tardia no crescimento pessoal (WINNICOTT, 1975, p. 99).

Estamos sugerindo, portanto, observar os apenados como sujeitos destituídos da permissão de criar, tendo seus impulsos criativos sufocados pelo ambiente carcerário, o que contribui para mantê-los distanciados de uma perspectiva de reorganização de si no mundo, de ressocialização propriamente - essa função tão apontada como objetivo do sistema carcerário, mas ao mesmo tempo tão negada na prática.

O sufocamento da subjetividade do apenado parece refletir-se na Lei de instituição do projeto, a qual determina objetivos genéricos como "oportunizar aos presos custodiados alfabetizados o direito ao conhecimento, à educação, à cultura e ao desenvolvimento da capacidade crítica" (PARANÁ, 2012, p.10). As entrelinhas do texto revelam um posicionamento que parece acreditar que o apenado não detém forma alguma de cultura, conhecimento e educação, devendo recebê-los passivamente, por intermédio do projeto, ou seja: abrindo mão do seu lugar de narrador da própria narrativa de vida. Além disso, podemos observar que o objetivo apontado pela Lei diz respeito mais a uma vida prática 
do sujeito, ao desenvolvimento de uma capacidade crítica, ou seja de uma capacidade analítica, de distanciamento daquilo com o que se está tendo contato, do que a uma vida subjetiva, de vivência literária, de humanização no sentido que vimos tratando até aqui. Mesmo na escolha do gênero textual, dentro do qual as produções dos apenados são avaliadas, a resenha, é possível perceber uma opção das secretarias envolvidas na instituição da Lei por uma escrita que demande um processo de reprodução do que se leu (afinal é preciso provar que se leu) e um posicionamento formal em vez de uma apropriação pelo diálogo do texto lido com as memórias e experiências pessoais.

Ao cabo, a estrutura do projeto, os objetivos e a escolha da resenha, como gênero textual avaliativo, revelam - por trás do discurso de ressocialização - uma intenção de cumprir mais facilmente com o direito ao estudo assegurado por lei ao apenado, uma vez que o projeto prevê muito menos reuniões presenciais do que a escola penitenciária costuma realizar, tornando-o uma forma mais viável e barata de conceder remição e aumentar o número de apenados com suposto acesso ao estudo, envolvendo menos profissionais, espaços e deslocamentos de internos.

Em oposição a essa perspectiva quantitativa e despropositada em relação à humanidade e às vivências dos apenados, buscamos realizar, a partir do momento em que entramos em contato com a população carcerária, uma maior valorização da subjetividade dos leitores. A voz de quem é silenciado reclama um lugar para se fazer ouvir, e entendemos o texto literário como espaço privilegiado nesse processo, seja como propulsor de uma escrita concreta, como motor da dinâmica criativa no processo de leitura, ou, ainda, como motivador da reconstrução do olhar criativo para a vida e para si mesmo, conforme Winnicott. Portanto não se trata, para nós, apenas de formar leitores críticos, mas de ensejar leitores criativos, leitores-autores, sujeitos capazes de ler-se e narrar-se, de assumir uma posição subjetiva num espaço protegido do sufocamento identitário próprio do ambiente carcerário, o espaço transicional, o espaço da arte, esse lugar da alteridade, da subjetividade, da vivência ficcional, onde o sujeito se atravessa e se ressignifica, recria-se.

Guiados por esse objetivo de centralização e emancipação da voz do encarcerado em sua narrativa de vida, propusemos, em parceria com o projeto de pesquisa "Leitura literária no ensino fundamental - ciclo 1: concepções e práticas", atividades optativas de leitura literária para os apenados. Os textos a serem 
analisados a seguir foram produzidos durante uma atividade em contato com a obra de Vinícius de Moraes. Com ela pretendíamos conferir liberdade leitora aos alunos, de forma bastante subjetiva, distante do exercício escolarizado, que, segundo Pennac (1995), propõe-se uma tarefa em troca de, no caso, alguns segundos de liberdade.

\section{Ler-se e reescrever-se: sobre as leituras escritas dos apenados}

No ano de 2013, como parte integrante do projeto de pesquisa "Leitura Literária no Ensino Fundamental - Ciclo 1: concepções e práticas", foi realizado o subprojeto "As marcas de entrada no mundo da leitura nas construções textuais-discursivas de alunos-detentos". Vinculado ao projeto "Remição pela Leitura" da Secretaria de Justiça, Cidadania e Direitos Humanos (SEJU-PR), o subprojeto foi efetivado por um estagiário que, paralelamente às atividades orientadas pela SEJU-PR, atuou como pesquisador de Iniciação Científica, norteado pelo objetivo de observar o aspecto humanizador da leitura do texto literário em um contexto de cárcere.

Ao longo dos seis meses de realização do subprojeto, seguiram-se rigorosamente as orientações para efetivação dos trabalhos relativos à remição de pena. Porém, paralelamente, foram implementadas ações que propiciaram momentos de leitura autêntica, uma vez que eram livres do sistema de "troca" instaurado pelo projeto da SEJU, em que cada livro resenhado equivale à redução de quatro dias da pena.

Muito embora o sistema fosse bastante rigoroso e a troca extremamente vantajosa para todos, não foi difícil identificar entre os detentos o desejo e a demanda por uma apreensão da leitura literária sob outro viés de valor. Muitos foram os casos de detentos que buscaram debater os livros lidos e mesmo requerer novos exemplares sem se preocuparem com o resultado em seus processos penais.

Nesse contexto, foi possível convidar os detentos a participarem de atividades que não resultariam em redução da pena. Apresentamos, a seguir, os efeitos obtidos pelo trabalho realizado com a leitura de uma coletânea de poemas de Vinicius de Moraes, poeta escolhido por sua relativa aceitabilidade entre as classes populares, dadas as vinculações com a canção popular. 
A proposta de leitura deu-se a partir da exibição do filme biográfico Vinicius (2005), de Miguel Faria Junior, como forma de introduzir os leitores numa ambiência poética, favorecida pelo ponto de vista do roteiro, que vincula vida afetiva e poesia como elementos constituintes de uma mesma experiência autoral. Em seguida, os detentos foram convidados a ler a coletânea de poemas para, por fim, escreverem livremente a respeito de um ou mais poemas por eles escolhidos.

Os textos a seguir são os excertos das criações dos detentos que mais chamaram a atenção devido à flagrante emergência subjetiva instigada pela literatura. Ao lado disso, neles também se destaca a evidente humanização, manifesta na própria tentativa especular de fazer-se representar por uma linguagem igualmente literária. Isto é, na medida em que os leitores em questão veem-se representados pela literatura, também buscam expressar-se por essa linguagem, criando e criando-se.

Chamou a atenção, ao longo dos trabalhos, a predileção de boa parte dos participantes da atividade pelo poema "Ausência". Apesar da incontestável proximidade temática entre o contexto de esvaziamento dos detentos e o que o "eu lírico" expressa no texto, é possível observar apropriações diversas do poema, reveladas nas criações de seus leitores.

$H^{1}$ inicia seu texto fazendo referência a suas memórias amorosas:

Estes versos me tocaram profundamente e me fizeram lembrar de uma fase da minha vida, na qual vivi um romance que a princípio tomou conta de mim de uma forma rápida e envolvente, mas com o passar do tempo, ésta paixão que era forte como o fogo foi se esvaindo, até o dia em que tudo se acabou por não haver uma paixão mútua (Transcrição de fragmento da produção textual de H).

Além do conteúdo relacionado ao tema do poema lido, observa-se, no fragmento, apesar das incorreções gramaticais, intenso cuidado com a linguagem. Primeiramente, vemos a tentativa de uma escrita formal, evidenciada pelo uso de vocábulos pouco frequentes na fala do contexto da detenção, como "romance" para namoro ou caso e "tocaram" para mexer, afetar. Ainda sobre esse as-

1 Nomes suprimidos para efeito de preservação das identidades dos apenados. 
pecto do zelo para com a formalidade dos enunciados, são patentes as expressões: "com o passar do tempo" e "paixão mútua".

Entretanto, parecem-nos ainda mais relevantes certos enunciados marcados esteticamente, parecendo afetados pela recente leitura do texto lírico. É o caso, por exemplo, de "um romance que a princípio tomou conta de mim", em que se percebe uma formulação metafórica, intensificada por expressão hiperbólica. Outro exemplo é a comparação também hiperbólica em "esta paixão que era forte como fogo".

Muito embora não seja possível atribuir à escrita de $H$ uma apropriação efetiva da linguagem poética ou literária, pode-se afirmar que houve um deslocamento da posição subjetiva, revelada através da escrita. O fenômeno, mais relacionado ao ato da leitura do que ao da escrita, leva a crer na possibilidade de o texto literário representar um elemento significativo na reelaboração do espaço transicional do sujeito. Isto é, a leitura de poesia e a possibilidade da livre expressão de suas impressões, deslocam o sujeito de um lugar de ser, imposto por sua condição de detento, para outros em que possa atuar movido pela busca em direção ao sublime.

O trecho a seguir, elaborado por $D$, ainda sob o registro de "Ausência", revela textualmente a possibilidade de expansão do espaço transicional:

Foi muito gratificante pois foi alguns momentos que me senti livre, mesmo preso, estive livre, pois minha mente chegou ir no meu passado, onde, tive lembrança maravilhosa com minha ex-namorada, [...] infelizmente foi uma lembrança boa e ruim; boa porquê tive as recordações dela, das canções que ela cantava pra mim enfim lembranças que me dá saldade. E a ruim é porque por motivo de imaturidade ela morreu em um acidente de carro que me deixou muito abalado, nossa e só em estar fazendo esta resenha e estar pensando nela já me dá vontade de chorar, não de tristeza, mas, de saldade uma saldade gostosa (Transcrição de fragmentos da produção textual de $D$ ).

No fragmento não se observa em $D$ a contaminação pela linguagem poética, como o que ocorreu com $\mathrm{H}$. Sua escrita caracteriza-se pelo relato pessoal em prosa, fundado na rememoração de acontecimentos passados. Destaca-se, entretanto, nas três primeiras linhas do trecho, a exposição da alteração sofrida por $D$ durante o processo de leitura. Em "momentos que me senti livre, mesmo 
preso, estive livre, pois minha mente chegou ir no meu passado", $D$ expressa o sentimento de liberdade vivido no processo de escrita, sem perder de vista, porém, a sua condição de detento e deixando claro que se trata de um movimento de reelaboração subjetiva, já que a própria criação textual afeta-o de modo significativo: "só em estar fazendo esta resenha e estar pensando nela já me dá vontade de chorar".

No trecho, $D$ também dá mostras de um movimento transicional ocorrido a partir do contato com o poema "Ausência". Desloca-se da condição de detento, tanto no que se refere à restrição da liberdade física quanto - e principalmente - em relação ao represamento da subjetividade. Ter saudade, chorar e, sobretudo, expressar suas fragilidades por meio da escrita, num empenhado resgate da subjetividade, marcado pelo apagamento do "eu", são movimentos que possibilitam a $D$ a evasão do contexto prisional.

Ainda tendo como referencial o poema "Ausência", E empreende em sua leitura um percurso semelhante àqueles desenvolvidos pelos demais detentos aqui citados. Retoma suas memórias prévias ao cárcere e faz uso de uma linguagem marcada por uma tentativa de exploração estética:

Foi tantos dias de amor com minha companheira, sorrisos, brincadeiras, sentimentos que marca e me faz falta e como faz, meu Deus Jeová sabe, é como construir um templo em meu coração e séculos para acabar com ele, que caminho doloroso (Transcrição de fragmento da produção textual de $E$ ).

Chama a atenção, nesse caso de leitura de "Ausência", a busca por modelos estéticos no universo religioso como solução para representar o deslocamento subjetivo. A imagem grandiosa do templo construído no próprio coração traduz a relevância da memória da mulher amada para o sujeito. Entretanto, a julgar pelos clichês em que se fundamenta inicialmente a metáfora, surpreende o arremate final da formulação. Isto é, de um lado, tem-se a imagem da construção do templo abrigado no coração, de outro a da sua corrupção. No imaginário mais comum, marcado por uma equilibrada antítese, a destruição dar-se-ia em instantes, como contraposição rigorosa à grandiosidade do templo. $\mathrm{O}$ que ocorre no texto de $E$, no entanto, é inusitado, destoando do senso comum. Em vez de ocorrer num átimo, a destruição do templo estende-se por séculos, quebrando, assim, a expectativa da antítese. Entretanto, o sentido decorrente parece mais 
coerente que nunca. Ao estender-se por séculos, o esfacelamento do templo produz um caminho doloroso, de onde se depreende tratar-se da representação do próprio sofrimento de $E$ no cárcere. Ver o templo definhar ao longo dos séculos, assistir à morte do amor, existir na infindável ausência do ser amado, só poderia ser traduzido por um enunciado que beira o bizarro, numa lógica quase barroca.

Outro caso de criação de procedimento de escrita que permitiu vislumbrar a apropriação subjetiva do discurso efetivado pelo poema é o texto de $R$, resultante da leitura de "Poema de Natal"2.

Enquanto isso?

Chorar faz parte do crescimento

fazer chorar desabrocha o arrependimento

Enterrar nossos mortos

E a insignificância dos nossos corpos

Mão para colher o que foi dado

E nunca o que foi roubado

Dedos para cavar a terra

E nos libertar da treva

Assim deverá ser a nossa vida

(Transcrição de fragmento da produção textual de $R$ )

$R$ organiza seu texto de forma centralizada, alternando seus versos aos do poema de Vinicius de Moraes. Busca conferir aos enunciados um tratamento estético, inicialmente, por meio do uso de rimas, ainda que imperfeitas (versos 2 e 3, 4 e 5, 6 e 7, 8 e 9), e reiterações vocabulares.

\footnotetext{
2 Para isso fomos feitos:/ Para lembrar e ser lembrados/ Para chorar e fazer chorar/ Para enterrar os nossos mortos -/ Por isso temos braços longos para os adeuses/ Mãos para colher o que foi dado/ Dedos para cavar a terra./ Assim será a nossa vida:/ Uma tarde sempre a esquecer/ Uma estrela a se apagar na treva/ Um caminho entre dois túmulos -/ Por isso precisamos velar/ Falar baixo, pisar leve, ver/ A noite dormir em silêncio./ Não há muito que dizer:/ Uma canção sobre um berço/ Um verso, talvez, de amor/ Uma prece por quem se vai -/ Mas que essa hora não esqueça/ E por ela os nossos corações/ Se deixem, graves e simples./ Pois para isso fomos feitos:/ Para a esperança no milagre/ Para a participação da poesia/ Para ver a face da morte -/ De repente nunca mais esperaremos.../ Hoje a noite é jovem; da morte, apenas/ Nascemos, imensamente.
} 
Destaca-se no texto o aproveitamento das imagens relativas à morte - "dedos para cavar a terra" e "treva" -, as quais são subvertidas para a construção de nova metáfora, agora concernente à expectativa de liberdade, já que os dedos que cavam a terra (verso 8) libertam da treva (verso 9) e levam à luz, inversamente ao que propõe o poema, em que a escuridão surge como consequência do apagamento de uma estrela ("Uma estrela a se apagar na treva"), talvez a última.

A cena de levantar-se da treva, de exumar-se e ir em busca da vida ("assim deverá ser nossa vida") expõe uma apropriação bastante peculiar do texto de Moraes e a criação de um novo significado, a partir do arranjo singular dos sentidos expressos no poema lido.

O movimento visto no texto de $R$, tendo sido uma produção consciente ou não, sinaliza para o fato de que a linguagem literária produz deslocamentos significativos da subjetividade. Nesse caso, ela revigora o sujeito, dando-lhe condições de ressignificar a pena ("Chorar faz parte do crescimento / fazer chorar desabrocha o arrependimento") e almejar o futuro (Assim deverá ser nossa vida).

Movimento semelhante pode ser visto na produção de $A$, a partir da leitura do poema "Epitáfio":

O epitáfio de Vinicios e espirado nele mesmo Aqui jas o sol que criou a aurora e deu a luz ao dia e aplascentou a tarde 0 mágico pastor de mãos luminosas que fecumdou as rosas e as despetalou. Vinicios era como um pastor de literatura que cultiva poema e colhe poesia que exala palavras, palavras que mechem com nossos coração e trás lágrimas, lágrimas gostosas. Vinicios eu poeta que nem se emportava com riquezas, ganância uma palavra que conhecia, mais já mais exercitará (Transcrição de fragmentos da produção textual de $A$ ).

Nesse fragmento, é possível observar um processo de apropriação de recursos específicos do gênero lírico, como: metáforas - "Pastor de literatura"; "cultiva poema e colhe poesia que exala palavras" - comparação - "Vinicios era como um pastor" -, anáfora e paralelismo - "exala palavras, palavras que mechem com nossos coração e trás lágrimas, lágrimas gostosas".

Ainda que de forma estruturalmente simples, $A$ procura, em seu texto, aproximar-se do fazer poético, o qual está intimamente ligado a uma linguagem marcada pela emergência do Eu. O enunciado "Vinicios eu poeta que nem se 
emportava com riquezas, ganância uma palavra que conhecia, mais já mais exercitará.", apresenta um deslize ortográfico, ausente nas demais produções de $A$. O suposto erro resulta da aglutinação do verbo ser flexionado no presente do indicativo (é) - e não acentuado graficamente (e) - com o artigo indefinido no singular (um) - cuja apócope do $m$ (u) demarca forte influência da oralidade -, resultando na inscrição "eu".

Irène Fenoglio (2006), pesquisadora da relação entre enunciação e psiquismo, em seus estudos, observa a possibilidade do lapso linguístico também na escrita. Amparada na psicanálise freudo-lacaniana, ela observa diversas situações de escrita em que o erro ortográfico gera novo sentido, revelando, portanto, uma emersão do sujeito. $\mathrm{O}$ aparente erro ortográfico pareceu-nos a manifestação do desejo de $A$ em estar mais próximo do poeta e mais apropriado do seu lugar de ser. "Vinicios eu poeta" representa a inscrição do deslocamento subjetivo, na medida em que cria um novo lugar para $A$, entre Vinicius e poeta, mergulhado na poesia, momentaneamente suspenso do cárcere.

\section{Considerações finais}

O potencial humanizador da literatura vem sendo constatado em diversas pesquisas que investigam os deslocamentos subjetivos decorrentes da leitura literária. No caso específico dos indivíduos em situação de cárcere, essa potência mostrou-se ainda mais acentuada. Num ambiente em que a desumanização é a tônica dominante, espaços de subjetividade e, portanto, de garantia do caráter humano dos indivíduos surgem como nota dissonante na pauta dos discursos que insistem na reserva dos bens culturais a certas elites e na consequente sobra do sistema ao que se considera "escória".

Nossa pesquisa, amparada em teorias de base psicanalítica, procurou romper algumas amarras sociais que impedem a ponderação de que o caráter transformador da literatura se aplica a todo e qualquer indivíduo a quem se permitam espaços de subjetividade.

A leitura de poesia e a possibilidade de livre expressão de significados pelos detentos revelaram-se extremamente fecundas. A apropriação da linguagem poética, ainda que incipiente, e, mais relevante, a assunção do lugar de poeta pelos detentos expõem o vital desejo de deslocamento da hodierna situação 
de cativo. Mais ainda, denunciam a busca pelo sublime e, assim, pela almejada condição de ser humano.

Se a literatura pode ser conceituada como um bem essencial à vida humana, se, conforme Candido, todos temos direito a ela, é justamente nos espaços de maior carência de humanidade que não deverá, jamais, estar ausente. 


\section{Referências}

CANDIDO, Antonio. Vários escritos. São Paulo: Duas Cidades, 1995.

. A literatura e a formação do homem. In: Remate de males. Departamento de Teoria Literária IEL/Unicamp, Número Especial Antonio Candido. Campinas, 1999. FARIA JR., Miguel. Vinicius. Direção de Miguel Faria Junior. Brasil, 2005, 110 min, Documentário.

FENOGLIO, Irène. Les événements d'énonciation graphique. Item (On line), 25 septembre 2006. Disponível em http://www.item.ens.fr/index.php?id=13752. Último acesso 01/agosto/2013.

FOUCAULT, Michel. Vigiar e punir: histórias da violência nas prisões. Tradução de Ligia M. Pondé Vassalo. Petrópolis, Vozes, 1986.

JOUVE, Vicent. A leitura. Tradução de Brigitte Hervot. São Paulo: Unesp, 2002.

LIMA, Sheila Oliveira; MELO, Henrique Furtado de. A leitura literária como revivência e ressignificação subjetiva de um aluno-detento. Revista Conexão UEPG, Ponta Grossa - PR, v. 9, p. 312-323, jul.-dez., 2013.

PARANÁ. Decreto-lei no 17329 de 8 de outubro de 2012. Institui o Projeto "Remição pela Leitura" no âmbito dos Estabelecimentos Penais do Estado do Paraná. Diário Oficial Executivo [do] Paraná. ed. 8814, p.10-11, 2012.

PENNAC, Daniel. Como um romance. Tradução de Lenny Werneck. Rio de Janeiro: Rocco, 1995.

PETIT, Michele. A arte de ler ou como resistir à adversidade. São Paulo: 34, 2009.

WINNICOTT, Donald Woods. O Brincar e a Realidade. Tradução de Jose Octávio de Aguiar Abreu e Vanede Nobre. Rio de Janeiro: Imago, 1975.

. Privação e Delinquência. Tradução de Álvaro Cabral. São Paulo: WMF Martins

Fontes, 2012. 